\title{
Existence and Many-One Identity
}

\author{
JASON TURNER
}

September 5, 2012

\begin{abstract}
C endorses the doctrine of Composition as Identity, which holds that a composite object is (plurally) identical to its many parts, and entails that one object can be (plurally) identical to several others. In this dialogue, $\mathrm{N}$ argues that many-one identity is conceptually confused. In particular, $\mathrm{N}$ claims it violates two conceptual truths: that existence facts fix identity facts, and that identity is no addition to being. In response to pressure from $\mathrm{C}, \mathrm{N}$ considers several candidate interpretations of the first slogan. Each imagines God issuing a divine existential decree that counts as 'fixing the existence facts', and then considers what questions about identity are left open by it. $\mathrm{N}$ eventually hits on an appealing interpretation of the slogan that $\mathrm{C}$ can neither undermine nor accommodate, and uses it to interpret the second slogan as well.
\end{abstract}

C: Well, hello there. I didn't expect to see you this fine morning. Sit down, do. And can I pour you a glass of lemonade?

N: Thank you, I should be happy to join you. But as for the glass of lemonade - well, you can't catch me out that easily.

C: Whatever do you mean?

N: You know full well that I don't think there are any composite objects. Had you offered me some particles-arranged-glasswise, filled with particlesarranged-lemonadewise, I would have happily agreed. But if I say I would like a glass of lemonade you'll catch me out in inconsistency.

C: Oh, you think too little of me. Have some particles-arranged-lemonadewise, then. But I do find this talk of particles-arranged-whatever-wise so very tiring. May I simply talk as though there were composite objects, and trust you to translate into particle arrangements on your own?

$\mathbf{N}$ : If you insist.

C: You know, if you would just start believing in composite objects you would save yourself a world of trouble. Don't translate the vulgar by your baroque phrasebook; agree with them! If you would just relax about composite objects, then your philosophy, like mine, could follow the common opinion.

$\mathbf{N}$ : It's tempting, but no. I am too much of a stickler for the rules of theory choice. Composite objects are otioise: everything they can do can be done by 
their constituent particles acting in concert. ${ }^{1}$ As I have no need for them, it would be extravagant to countenance them anyway. Ochkam's razor remains my guide.

C: Oh, mine too! I'd never ask anyone to defy Ockham. But my composite objects aren't any extra ontological commitment, for they are identical to the particles that make them up. ${ }^{2}$

N: Excuse me? I don't think I quite understand. According to you, I am holding a glass - let's call it Gary. Are you telling me that Gary is identical to each of the particles that make it up? That cannot possibly be right. Suppose Peter and Paul are two distinct particles that help make up Gary. If Peter and Paul are each identical to Gary, then they'll be identical to each other, by the transitivity of identity. That's a reductio - unless you want to give up the transitivity of identity? That would be a high price to pay!

C: Oh, no, you misunderstand me. The glass isn't identical to each of its particles. It's identical to the particles taken together. If Peter and Paul were the only (simple) parts of Gary, then Gary wouldn't be identical to Peter, and wouldn't be identical to Paul, but would be identical to Peter and Paul taken together in just the way that Led Zeppelin is identical to Jimmy Page, John Bonham, John Paul Jones, and Robert Plant, even though none of these four are by themselves identical to Led Zeppelin. ${ }^{3}$

N: Ahh, I think I understand. This is related to your laid-back linguistic attitude, yes? Like me, you think that reality consists only of the simple particles. But, unlike me, you are happy to talk about some particles as though they composed an object. Just as 'Led Zeppelin' is a syntactically singular name with a semantically plural referent, for you, the name 'Gary' is syntactically singular but functions semantically like a name for some particles. So you can say that the particles are identical to Gary, but that's just a slightly misleading way of saying that 'Gary' refers collectively to those particles.

\footnotetext{
${ }^{1} \mathrm{~N}$ seems to have been convinced by Trenton Merricks' (Objects and Persons, Oxford UP, 2001, pp. 56-79) causal exclusion argument for mereological nihilism.

${ }^{2} \mathrm{C}$ is endorsing the thesis of Composition as Identity. It has been discussed sympathetically in D. M. Baxter, "Identity in the Loose and Popular Sense", Mind 97 (1988), pp. 575-82 and "Many-One Identity", Philosophical Papers 17 (1988), pp. 193-216; D. Lewis, Parts of Classes (Malden, Mass.: Blackwell, 1991), in section 3.6; and T. Sider, "Parthood", The Philosophical Review 116 (2007), pp. 51-91, in section 3. It has also been straight criticized, in (inter alia) P. van Inwagen, "Composition as Identity", Philosophical Perspectives 8 (1994), pp. 207-20, reprinted in his Ontology, Identity, and Modality (Cambridge UP, 2001), pp. 95-110; B.-U. Yi, "Is Mereology Ontologically Innocent?", Philosophical Studies 93 (1999), pp. 141-60; and K. McDaniel, "Against Composition as Identity", Analysis 68 (2008), pp. 128-133. Below, N will offer criticisms largely independent of van Inwagen's, Yi's, and McDaniel's.

${ }^{3} \mathrm{C}$ is showing a preference for Sider's formulation of the view over Baxter's. Baxter relativizes identity to 'counts' and defines a many-one 'cross-count' identity. He then allows that Gary may be identical to each of Peter and Paul in a sort of cross-/intra-count identity mixture, as we could deny the identity of Peter with Paul by denying the transitivity of such mixtures.
} 
C: That's a perfectly respectable view, but it's not mine. On the view you outlined, if we're being metaphysically serious, we'll have to say 'there is no glass'. But so long as we're being sloppy, we can say 'there is a glass', and it counts as true because there are particles arranged glasswise. And further, while being sloppy, we can truly say 'the particles arranged glasswise are identical to the glass', because we have a fancy semantic theory for our sloppy talk that has the same particles satisfying 'are arranged glasswise' and 'is a glass'.

But my view isn't fancy semantics. I think that, even when speaking with all metaphysical seriousness, we can truly say that there is a glass, and that it identical (collectively) to the particles that make it up.

Here's one way to see the difference. The theorist with the fancy semantics needs there to be a 'bottom level' of particles, so the singular terms can have some plural referents. He can't allow (when speaking sloppily) that there is any 'atomless gunk': objects with proper parts each of which has proper parts. ${ }^{4}$ But I can! Gary might be identical to Peter and Paul; Peter might be further identical to two parts, Mary and Martha, each of which are identical to two further parts, and so on.

$\mathrm{N}$ : Why, that is a truly radical thesis! It depends on being able to make sense of the idea that identity - real, genuine identity, and not something second-rate cooked up with deviant semantics - can be many-one. Well, I can see why you think you can have your glass without ontological commitment, that's for sure. But I worry that it's not coherent.

C: In what sense is it incoherent? You've understood me well enough, it seems; better, at any rate, than if I had told you that the vorpal blade was slithy or that blue ideas slept furiously.

N: Well, maybe not incoherent. But I think it relies on a subtle conceptual confusion. The relation can't really be identity, if it is many-one. That is abhorrent to the very concept of identity!

C: Perhaps it is. Philosophy is a risky business, and we all flirt with subtle conceptual confusions now and again. But it certainly doesn't seem confused to me. Can you point out some conceptual truth involving identity that I'm committed to denying? And please don't say that it is a conceptual truth that identity is not many-one; even if it were right, it surely couldn't convince me.

N: Well, you'll surely agree that it's a conceptual truth that identity obeys Leibniz' Law, yes?

C: Certainly, so long as we add in suitable caveats for predicates like 'was so-called because of his size' and so on.

\footnotetext{
${ }^{4}$ Cf. Sider, "Van Inwagen and the Possibility of Gunk", Analysis 53 (1993), pp. 285-9.
} 
N: Yes, of course. Well, suppose that a farmer has four quarter-acre fields which together compose a further one-acre field. Surely you'll agree that the former are four fields and the latter is one field. But then by Leibniz' Law, they must be distinct. ${ }^{5}$

C: Not at all. You assume that whatever is four fields is not one field, and whatever is one field is not four. I don't. The four fields are indeed four; but they are also one. And the one field is indeed one; but it is also four.

That's not to say that some statements about the fields' fourness or oneness aren't more common or suitable than others. The farmer has one parcel of reality, which we can think of in a four-field or a one-field way. When we're thinking of the parcel of reality in a four-field way, we're inclined to say 'The four fields are four'; when we're thinking of them in the one-field way, we're inclined to say 'The one field is one'. We're very seldom inclined to say 'The four fields are one,' because we don't tend to shift ways of thinking in mid-sentence. But that doesn't mean it's false.

N: Ahh, I see better. Well, you've certainly thought this through. Still, there is something about the idea that bothers me deeply. Hmm ...

C: Have you discovered the source of your discontent with many-one identity?

N: I believe I have. In the Tractatus, ${ }^{6}$ Wittgenstein claimed that identity is not a relation. I don't think that's quite right, but Wittgenstein was getting at something important about identity: it's not something added to what exists. It's unlike run-of-the-mill relations, such as being five feet from. With run-of-the-mill relations, once you've got some things there's a further question where these relations go. But once you have some things, identity is settled: everything is identical to itself, and distinct from everything else. One way of putting this is that identity is 'thin': there's nothing to identity over and above the existence of the individuals in question. But if identity could be many-one, it would be 'thick': Gary's being collectively identical to Peter and Paul would go beyond the mere existence of Peter and Paul.

But if identity is many-one, then the existence facts don't fix the identity facts. We can imagine God saying, 'Let there be three things'. As commanded, three things - Alice, Ben, and Cynthia, say - pop into existence. And, of course, each is identical to itself. But there's still a left-over identity question: is one of these identical to the other two? Is Cynthia (collectively) identical to Alice and

\footnotetext{
${ }^{5} \mathrm{~N}$ here echoes Baxter, "Identity in the Loose and Popular Sense", pp. 580-1 and Lewis, op. cit., p. 87.

${ }^{6} \mathrm{~N}$ is thinking of propositions $5.5301-5.5303$.
} 
Ben? The divine decree doesn't settle it - as it should, if existence facts fixed identity facts. ${ }^{7}$

C: You may be right, but I need to hear more about this thin conception of identity. What is it? And why think it incompatible with many-one identity?

$\mathbf{N}$ : Well, part of the thin conception is that all identity questions are settled by answers to existence questions. In slogan form, we might say that the existence facts fix the identity facts.

C: Are you expanding your ontology to include facts now? I have always known you a nominalist of the most austere sort.

N: No, my apologies; I was taking your hospitality with regard to talk of composite objects to extend to other categories. What I really want to say is that how the world is existence-wise is fixed by how it is identity-wise. But as a slogan, 'the existence facts fix the identity facts' sounds less cumbersome.

C: Consider my hospitality so extended; I certainly understand you better now. But I do not understand you quite as well as I would like. What do you mean by 'fix' here? If someone tells me that some A-facts fix some B-facts, I would expect a supervenience thesis: no two possible worlds agree on the A-facts and disagree on the B-facts. But I believe in classical mereology, and have no reason to countenance possible worlds that agree on what exists but disagree on what is composed of what. But in this case I also have no reason to countenance possible worlds that agree on what exists but disagree about how identity is spread around.

N: No, by 'fix' I have in mind a conceptual relation. The lack of metaphysically possible worlds that agree on existence but disagree on identity isn't enough; there can't be any conceptually possible worlds where the two come apart. My thought is essentially this.

C: Hmm... yes, I think I see the idea. But I'm not entirely convinced yet of this 'existence-facts fix identity-facts' thesis you're trumpeting. Or, at least, I'm not convinced of it in any form that threatens many-one identity.

In your story, you have God saying, 'Let there be three things.' But what does that mean, unless 'Let there be a thing $x$, and another thing $y$, and another thing $z$, and let $x$ and $y$ and $z$ all be distinct from each other'? If that's what God is saying, she isn't really fixing just the existence facts with her decree. She's simultaneously fixing both the identity and the existence facts.

N: I had God saying 'Let there be three things'; call this sentence 'Decree'. Let's call your complex sentence with ' $x$ ', ' $y$ ', and ' $z$ ', 'Count'. My argument assumed

\footnotetext{
${ }^{7}$ A similar point is made in R. P. Cameron, "Composition as Identity Doesn't Settle the Special Composition Question", Philosophy and Phenomenological Research 84 (2012), pp. 531-54, on pp. 551-3. Cameron there draws on an earlier (and differently-titled) draft of this paper.
} 
that Decree is just about existence. You rightly point out that Count isn't just about existence, but about existence and identity both. But while I grant that Decree entails Count - I have to, since I think existence facts fix identity facts - and I grant that Count clearly entails Decree, I don't see why I should accept that Count and Decree say the same thing.

If I thought that all meaningful clams could be analyzed into first-order logic, then since the only plausible first-order analysis of Count is also the only plausible first-order analysis of Decree, I could see the pressure to equate the two. But I deny that all meaningful claims can be analyzed into first-order logic. I understand 'there are infinitely many blahs' perfectly well, although it lacks a first-order analysis. But if 'there are infinitely many blahs' cannot be given a first-order analysis, I see no reason to think that 'there are three blahs' can be, and so no reason to think that Decree and Count say the same thing.

C: Fair enough. I don't want to insist that Decree must be analyzed as Count. But I'm still not convinced that Decree is entirely about existence. After all, Decree involves the concept three. My complaint isn't that I can't understand three unless analyzed into something involving identity; my complaint is that I can understand it, and my understanding of it shows it to be more closely allied with identity-like concepts than with existence-like concepts. What is it for there to be three of something? Well, it's for the somethings to be parceled out into three different chunks - that is, three distinct chunks - that is, three non-identical chunks. So if God is deploying the concept of three in her decree, she is not decreeing purely existentially.

N: Ahh, I see your worry now, although I'm not moved by it myself. But anyway, I think it's incidental to the example. God doesn't have to deploy the concept three to make an existential decree; she can simply say 'Let Alice, Ben, and Cyntha exist.' That's a purely existential decree - at least, there's no temptation to see anything identity-like in it. But, once again, we can see that if identity is many-one it won't fix the identity facts, for we can still wonder whether Cynthia is (collectively) identical to Alice and Ben.

C: Now you have God issuing a decree with names. But named decrees won't fix identity facts: God can say, 'Let Hesperus and Phosphorus exist,' without settling whether Hesperus is Phosphorus.

N: Well, now, that's not clear to me. Suppose God makes a decree; we ought to distinguish the sentence she uses and the singular proposition she thereby expresses. Suppose we think of singular propositions as literally containing the objects they're about. We can imagine the sentence 'Let Hesperus and Phosphorus exist' expressing a proposition containing just one object twice, as it would if 'Hesperus' and 'Phosphorus' co-referred, or we can imagine it as containing two objects, as it would if the terms did not co-refer. But once we know which proposition God decreed, it seems to me she will have settled the identity facts. 
It's just that our ignorance about the 'shape' of the proposition decreed leads to ignorance of these identity facts.

C: Hold on - if neither Hesperus nor Phosphorus exist yet, presumably neither do any propositions containing them as constituents. But if these propositions don't exist, then presumably God cannot decree them, either.

N: Oh, I was just trying to be illustrative. The point goes through just as well if we presume that singular propositions don't have the individuals they're about as constituents, and can exist in the absence of these individuals. Say that two propositions are 'co-singular' if and only if, had they been about any objects at all, they would have been about the same object.

The decree 'Let Hesperus and Phosphorus exist' is a conjunctive decree. I claim two things. First, since we're ignorant as to whether the conjuncts of this decree are co-singular or not, the identity facts created by this decree seem open to us. And second, the decree itself settles the identity facts: if the conjuncts are co-singular, the decree settles that just one thing exists (thanks to this decree, anyway), and if they're not, the decree settles that just two things exist (thanks to this decree).

C: That's a bit better, but you're still asking me to believe in some pretty heavy machinery. I'm inclined to think that singular propositions do have the individuals they're about as constituents, and can't exist if those constituents don't. So I'm not very moved by the example.

But I wouldn't be moved if I thought otherwise, either. You're now treating 'fix the existence facts' as 'fix the truth-values of the singular propositions'. But to make your argument work, you need the co-singularity facts to be fixed independent of the existence facts. Why should I believe that? What if I thought that there were two propositions - the proposition that Hesperus exists, and the proposition that Phosphorus exists - and that, when they're false, there is no fact of the matter about their co-singularity? Then God can decree, in essence, that they both be true while leaving it open whether her decree also make them co-singular or not.

Now, maybe that's not possible. But it certainly seems conceptually possible. At least, I have no trouble imagining singular propositions in this way, and when I do, I have no trouble imagining two possible worlds that agree on which singular propositions are true but disagree on the co-singularity relations between them.

N: Yes, I see what you mean - that seems imaginable to me, too. I'm not entirely convinced it is imaginable - I'm tempted to say that if the co-singularity relations are up for grabs, the propositions aren't in fact singular - but I don't see quite how to make that argument stick. At any rate, you've convinced me that there's potential wiggle-room between 'fixing the existence facts' and 'fixing the truth-values of the singular propositions'. I'll need to think a bit more about what I mean by 'fixing the existence facts' that closes this wiggle-room. 
N: Suppose instead of making just one decree, God makes three decrees. She says, 'Let there be something new,' repeated some number of times, and then says 'okay, I'm done.' Call this an act of decree.

When I talk about 'fixing the existence facts,' I'm talking about what God would do if she were to perform an act of decree. And I claim acts of decree fix the identity facts, too: once she's made an act of decree, there are no further questions for God to settle about which of the things that came into existence are identical to which. I claim this is a conceptual truth about identity: we can't make sense of there being any questions about identity left to settle once the act of decree is finished.

C: How am I supposed to think about the 'new' in God's decree? Does 'something new' mean 'something not identical to anything that already exists'?

$\mathbf{N}$ : I wasn't thinking that God had anything specifically about identity in mind. The idea, rather, is just that God doesn't want to make redundant decrees. If Alice already exists, and God says 'let there be something,' then in some straightforward sense her decree is automatically fulfilled. But it's fulfilled without being effective: things wouldn't have been any different if she hadn't made the decree. When she says 'something new', she's really just trying to make sure that her decree is effective. If non-identity is needed to make it effective, then so be it; but then the distinctness of the newly created things with what already exists is a consequence of her decree, not a part of its explicit content.

C: But if the existential decree 'let there be something,' is already satisfied by Alice, then it looks like 'let there be something new' can't be just a pure existence decree - the 'new' is doing some serious work. And what is that work, if not the work of non-identity?

$\mathrm{N}$ : I agree the 'new' is doing serious work. But I don't see why the work has to be the work of non-identity. Suppose there was nothing but some water, and God said, 'Let there be some new water'. Presto - new water comes into existence. But it's strange to think that, in creating more water, God has been thinking thoughts about identity. What would such thoughts be? ${ }^{8}$

C: Well, after the decree there will be more water molecules than before, right? So the decree might mean 'let there be some water molecules not identical to any water molecules that exist now'.

N: Okay, so suppose that, instead of water, all that existed was some perfectly homogenous fluid - 'hwater' — that occupied a continuous region of space.

\footnotetext{
${ }^{8} \mathrm{~N}$ is grateful to an anonymous referee for the suggestion.
} 
Then God says, 'let there be some new hwater', after which the region of space occupied by hwater is bigger. Since 'hwater' isn't composed of molecules, she can't be thinking anything about molecule-identity here.

C: How about 'let there be some portions of hwater not identical to any portions of hwater that currently exist?'

N: But why think that, after the decree, there are any new portions of hwater? There's certainly more hwater; but maybe that's because all the portions grew.

There are continuum-many extended regions of hwater both before and after the decree, so there will be a one-to-one correspondence between hwateroccupied regions before the decree and hwater-occupied regions after. In fact, there will be many, and some of these will preserve subregion-relations. Maybe one of these subregion-preserving one-to-one correspondences is actually the identity relation on portions of hwater. That is, every extended portion of hwater after the decree is a portion that existed before, albeit in a smaller region.

C: What about the point-sized regions?

$\mathbf{N}$ : Maybe there aren't any. God might be making the decree in a universe with a 'gunky' space.'

C: Okay, so God can create new hwater without smuggling in anything about identity. Remind me why this is supposed to cause problems for my view?

N: Well, if God can decree new hwater without covert appeals to non-identity, it would be ad hoc to deny her ability to create, say, Alice, Ben, and Cynthia this way. (Granted, if Ben is created this way, he will be non-identical to anything we had before; but that's metaphysically downstream, as it were, of the decree itself.)

So suppose God performs an act of decree, one consisting of three individual decrees. And suppose that Alice, Ben, and Cynthia are the three things that pop into existence. That's consistent with either Cynthia being (collectively) identical to Alice and Ben, or Alice being (collectively) identical to Cynthia and Ben, or none of them being (collectively) identical to the other two, and so on. If identity is many-one, fixing the existence facts with an act of decree doesn't fix the identity facts.

C: Right, yes - that was the argument. You'll not be surprised that I do not like it, although I haven't decided yet where it goes wrong. Just give me a moment to think about how to respond...

\footnotetext{
${ }^{9}$ For discussion of such spaces see F. Arntenius, "Gunk, Topology, and Measure", in D. Zimmerman (ed.), Oxford Studies in Metaphysics volume 4 (Oxford UP, 2008), pp. 225-47 and J. S. Russell, "The Structure of Gunk: Adventures in the Ontology of Space", ibid., pp. 248-74.
} 
C: Let me make sure I have this right. Your argument is that it is conceptually possible that God perform an act of decree which gets him Alice, Ben, and Cynthia without thereby settling whether, say, Cynthia is collectively identical to Ben and Alice, right? And if what I'm calling 'collective identity' were identity, this wouldn't be conceptually possible, so my protestations to the contrary must be confused. Do I have that right?

N: That sounds a fair way to put my point.

C: I deny that this act of decree leaves open the collective identity facts. Suppose Cynthia is in fact collectively identical to Alice and Ben. Then any decree God issued that brought Cynthia into existence had to also bring Alice and Ben into existence (if they weren't already around), and left no room for Cynthia's distinctness from Alice and Ben. After all, they are Cynthia, so whatever happens to Cynthia must happen to them! And since we can't imagine Cynthia not being identical to Cynthia, we can't imagine Cynthia not being identical to Alice and Ben.

It might seem to you that you can imagine Cynthia failing to be identical to Alice and Ben, but this is simply because you have not taken on board their identity. Just as, once you take on board the identity of Hesperus and Phosphorus you lose the illusion that they could be distinct, once you take on board the collective identity of Cynthia with Alice and Ben you lose the illusion that they could be distinct as well.

$\mathbf{N}$ : Oho! So you're going to insist that collective identity facts are conceptually necessary? But collective identity is, on your view, composition. So the composition facts must be conceptually necessary, too. Funny - I never had you pegged for a mereological essentialist, but you turn out to be one of the first order!

\section{C: I guess I am, at that. What of it?}

N: The vulgar aren't mereological essentialists; they'll insist that Gary the glass will continue to exist even if its particulate part Peter is destroyed. I thought you prided yourself on agreeing with the folk in ontological matters.

C: Well, I need not disagree with them. Perhaps 'Gary' is a name not for an individual object, but for a sequence of successive objects, picking out a slightly different mereological fusion at each moment. At one moment, when Peter exists, 'Gary' picks out an object with Peter as a part; at a later moment, after Peter's destruction, 'Gary' picks out another object lacking Peter. I'll grant that the details are bound to get a bit messy, but I don't see why such a story can't be told.

N: Well, I'll not push you on the tellability of your story. Notice who's translating with a baroque phrasebook now, though. 
But even with your mereological essentialism on board, I don't think you're out of the woods when it comes to identity facts being fixed by existence facts. Let's go back to God's acts of decree. Suppose God began by saying 'Let there be something new,' and Alice popped into existence. God said again 'Let there be something new,' and Ben popped into existence. Do we now have Cynthia as well, or did God have to make a further decree to bring Cynthia into existence?

C: That's a good question, and one I have lately pondered. In a certain sense, the answer is clearly 'no'. Since Alice and Ben existed after the second decree, and Cynthia is identical to Alice and Ben, Cynthia must have existed after the second decree. That's just Leibniz' Law.

But what I hadn't noticed until recently was that the sense in which Leibniz' Law guarantees Cynthia's post-decree existence is a distributive one. The first two decrees have it that Alice and Ben each exist; they don't, on their own, guarantee that there is some (one) thing which Alice and Ben are collectively identical to. So, after the second decree, Cynthia 'exists' in just the sense that the things to which Cynthia is collectively identical each exists. ${ }^{10}$ The point could maybe be put semantically: Once Alice and Ben exist, 'Cynthia' will be a referring term, but it might be only a plurally referring term. God might need to do something else to make sure that Cynthia be a single thing, or - if you prefer - that 'Cynthia' work as a singular, rather than merely a plural, term.

N: Then I don't see how you've avoided my argument, even granting your strong form of mereological essentialism. God performs an act of decree consisting of three individual existential decrees. The first one brings Alice into existence; the second brings Ben into existence. What will the third do? It may bring Cynthia into existence - that is, make Cynthia exist as a single thing rather than just collectively as Alice and Ben - or it may instead bring some other, entirely distinct, thing into existence. If the decree does the first, the world will have an instance of many-one identity; if it does the second, the world won't. So performing an act of decree won't fix the identity facts after all.

C: Perhaps I should insist that there's something incoherent about the very act of a 'pure' existential decree in the first place. Maybe God cannot issue a 'bare' existential decree, but must always include a specification of what sorts of identity relations the newly created thing stands in.

N: Perhaps you should; you've already come dangerously close several times. And then I couldn't run my argument, but I don't see that it would help with my ultimate complaint. My argument was based on the Tractarian idea that identity wasn't something extra, over and above existence, but somehow just an epiphenomenon that came from having a world with things in. If God cannot

\footnotetext{
${ }^{10} \mathrm{C}$ is getting this from Cameron, op. cit..
} 
simply make existential decrees, but must mix a heavy dose of identity specification in with them, then identity would seem to be indeed something extra, added to existence.

C: Okay, then I won't insist that. I'll let you run your argument, but I'll simply deny that the existence facts fix the identity facts in the sense you articulate.

When you were first running the argument, I was thinking the slogan meant that acts of divine decree plus their effects - the things they bring into existence - fix the identity facts. But now I see that you intended something stronger: an act of divine decree itself fixes the identity facts.

With my essentialism, I can grant that the decree, coupled with its existential effects, fixes the identity facts. If God makes a decree, certain things will come into existence, and bring with them their identity relations. When Cynthia comes into existence, since Cynthia just is Alice and Ben, there's nothing left for God to do to make Cynthia identical to Alice and Ben.

But the performance of the decree leaves it open which things will come into existence, and so leaves it open what the identity facts will be. I agree: this doesn't fix the identity facts. But I don't see why it should! Suppose God decrees, 'let something exist,' and Socrates comes into existence. Socrates is essentially rational, so something rational must have also come into existence. In your strong sense, the rationality facts aren't fixed by the existential ones; in my weak sense, they are. But I say that my weak sense is fixing enough: by bringing Socrates into existence, God doesn't have to do anything else. God gets many-one identity facts just as automatically, for just as free, as she gets facts about individuals' essences.

N: Well, I'm inclined to think that God doesn't get facts about essences for free. But let's not haggle about that. Even if I grant that she does, I don't think you've yet addressed my complaint. It wasn't merely that, if identity were many-one, God would have to 'do something else'. It was that identity would have to be a genuine addition to being - something that goes beyond mere existence.

Surely you'll agree that rationality is an addition to being. Even if it's part of Socrates' essence to be rational, and even if it's impossible to have one without the other, that Socrates exists and that Socrates is rational are distinct facts. I say something different about Socrates when I say he is rational than I do when I say he exists. Rationality is something over and above existence. It's something added to Socrates - perhaps it must be added to Socrates, in order to make him Socrates - but it's still an addition. My Tractarian picture denies that identity is even this much of an addition. Rationality makes a distinction in being, and is used to differentiate some objects from others. Identity does not.

C: I'm getting more skeptical of this Tractarian picture by the moment. But your last comment has intrigued me. Can you say any more about it?

$\mathbf{N}$ : Okay, let me try. Think of a name-free idealized language of metaphysics; perhaps it's infinitary, but let's not fuss about that. If you think of all the sen- 
tences open in just one variable that you can make with its logical vocabulary and, say, the predicate 'is rational,' you'll find conceptual possibilities where some things satisfy those open sentences but others don't. But if you consider all the open sentences you can make with logical vocabulary and an identity predicate, any possibility you can imagine will be one where either everything satisfies that predicate or none do.

C: That's because the language is name-free, though, right? Otherwise plenty of identity-only open sentences will discriminate objects.

$\mathbf{N}$ : Indeed. The idea is that identity doesn't discriminate between objects. If we used names, then identity plus some de re facts will discriminate objects. But it's not identity doing the discrimination, but the additional de re facts.

Begin with a name-using language, and exchange the names for predicates. For instance, for 'Socrates' we have 'Socratizes,' and we translate all uses of 'Socrates' for 'the Socratizer'. ${ }^{11}$ Sentences which before discriminated between objects by using names now do so thanks to predicates. But this reveals that it wasn't identity doing the discrimination at all. It was Socratizing that discriminated, and Socratizing can discriminate without using identity, if it likes. There are conceptual possibilities where ' $x$ Socratizes' applies to some but not all objects. But Socratizing, like rationality, is something beyond identity, and something that should discriminate between objects.

C: I see. That is a helpful illustration. So the idea is that a property or relation is an 'addition to being' if there are possible situations where sentences open in one variable, using only logical vocabulary and a predicate that expresses this property or relation, are satisfied by some but not all things. Is this also supposed to help specify what it is for one kind of fact to be fixed by another?

N: You've got me right on 'addition to being,' but I wasn't using it to further flesh out fact-fixing. I was just trying to clarify the Tractarian picture.

Having done so, though, I have another argument against many-one identity. Surely you'll agree that, if identity is many-one, then it is an addition to being, in my sense. After all, in the scenario where God creates Alice, Ben, and Cynthia, Cynthia satisfies 'is identical to some $x$ and some $y$ taken together', but Alice and Ben do not. On the Tractarian picture, identity is no addition to being. So if the Tractarian picture is right, many-one identity is incoherent.

C: Oh, certainly, identity must be an addition to being, in the sense you've outlined. And I agree that, if the Tractarian picture says otherwise, then many-one identity is incompatible with it. So much the worse for the Tractarian picture, say I! Had I realized just what it amounted to, I should have never gone along with it, nor tried to accomodate the 'existence fixes identity' slogan it inspired.

${ }^{11}$ Cf. W. V. O. Quine, Mathematical Logic (Harvard UP, 1940), section 27. 
N: I can see that your view gives you good reason to reject the Tractarian picture, but it still seems eminently independently plausible. I prefer it over agreeing with the vulgar about glasses of lemonade, at any rate, and so I'm afraid I cannot go along with you in accepting that composition is identity.

C: Perhaps not. It seems that I must convince you that the view's charms are worth giving up your old-fashioned thoughts about identity. Alas, I cannot do so now; time draws on, and I must get to my appointment.

$\mathrm{N}$ : That is too bad. I have enjoyed our chat, and would have liked to hear more about your view's charms. Perhaps next time, then! And once again, many thanks for the particles-arranged-lemonadewise. ${ }^{12}$

\footnotetext{
${ }^{12}$ Thanks to Ted Sider, Robbie Williams, an anonymous referee, and especially Ross Cameron
} for helpful comments and conversation. 